\title{
A VIAGEM DE HENRIQUE SCHUTEL AMBAUER PELA PROVÍNCIA DO RIO GRANDE DO SUL
}

\author{
VALTER ANTONIO NOAL FILHO ${ }^{1}$ JOSÉ NEWTON CARDOSO MARCHIORI $^{2}$
}

\section{RESUMO}

Com base no manuscrito inédito A Província do Rio Grande do Sul-descripção e viagens, resultante de excursão realizada ao final da década de 1850 pelo milanês Henrique Schutel Ambauer (1840-1899), faz-se uma análise de tópicos relativos a costumes, a hábitos culinários hoje esquecidos, à vida rústica dos habitantes do interior, à natureza quase intocada, à influência dos fatores climáticos no cotidiano dos viajantes, à rusticidade dos caminhos terrestres, à importância dos rios nos deslocamentos de outrora e à hospitalidade dos gaúchos, que variava da mais calorosa acolhida à frieza de um pouso ao relento.

Palavras-chave: Henrique Schutel Ambauer, Rio Grande do Sul, Viajantes.

\begin{abstract}
[The journey of Henrique Schutel Ambauer by the Province of Rio Grande do Sul, Brazil]. Based on the unpublished manuscript A Provincia do Rio Grande do Sul-Descripção e Viagens, which arose from a journey accomplished by the Milanese Henrique Schutel Ambauer (1840-1899) in the end of 1850 s, an analysis is developed focusing on topics related to costume, nowadays forgotten cooking habits, rustic life of the inhabitants of the countryside, unspoiled nature, the crucial influence of climatic factors in the routine of the travelers, the rusticity of terrestrial paths, the importance of rivers for journeys in former times and the gauchos hospitality, which varied from a warmest welcome to a coldness of landing outdoor. Keywords: Henrique Schutel Ambauer, Rio Grande do Sul State, Travelers.
\end{abstract}

\section{INTRODUÇÃO}

Henrique Schutel Ambauer é autor pouco conhecido na estante sul-rio-grandense de viajantes, pelo simples motivo de seu relato nunca ter sido integralmente publicado. Cumpre salientar, de início, que após sua viagem pelo interior da província do Rio Grande do Sul ele viveu por muitos anos como professor de música, na cidade de Rio Grande.

O texto examinado corresponde a uma cópia microfílmica do manuscrito original, pertencente ao acervo da "Bibliotheca RioGrandense". O original tem a data de 1873 e se encontra em autógrafo no arquivo do Instituto

1 Graduado em Comunicação Visual (1983) pela Universidade Federal de Santa Maria, instituição em que trabalha.valterantonionoalfilho@gmail.com

2 Engenheiro Florestal, Dr. Bolsista de Produtividade em Pesquisa (CNPq - Brasil). Professor Titular do Departamento de Ciências Florestais da Universidade Federal de Santa Maria.
Histórico e Geográfico Brasileiro ${ }^{3}$, na cidade do Rio de Janeiro. Resta informar que o presente artigo resume pesquisa desenvolvida ao longo de muitos anos sobre o autor e a obra em foco.

\section{O VIAJANTE AMBAUER}

Natural de Milão, Enrico Schutel Ambauer nasceu em 7 de julho de 1840, filho de Mattia Ambauer e de Elisa Schutel. Muito jovem, com apenas 17 ou 18 anos, deixou a sua pátria e veio para o Brasil, empreendendo, sem demora, a viagem pelo interior da província do Rio Grande do Sul, cujo texto, ainda inédito, é objeto do presente artigo.

Tomado de curiosidade incomum sobre as coisas do Rio Grande, o jovem adaptou-se rapidamente ao país e à língua portuguesa, como se pode comprovar pela qualidade textual de seu manuscrito e pelo abrasileiramento do nome de batismo com que firma sua obra: "Henrique". 

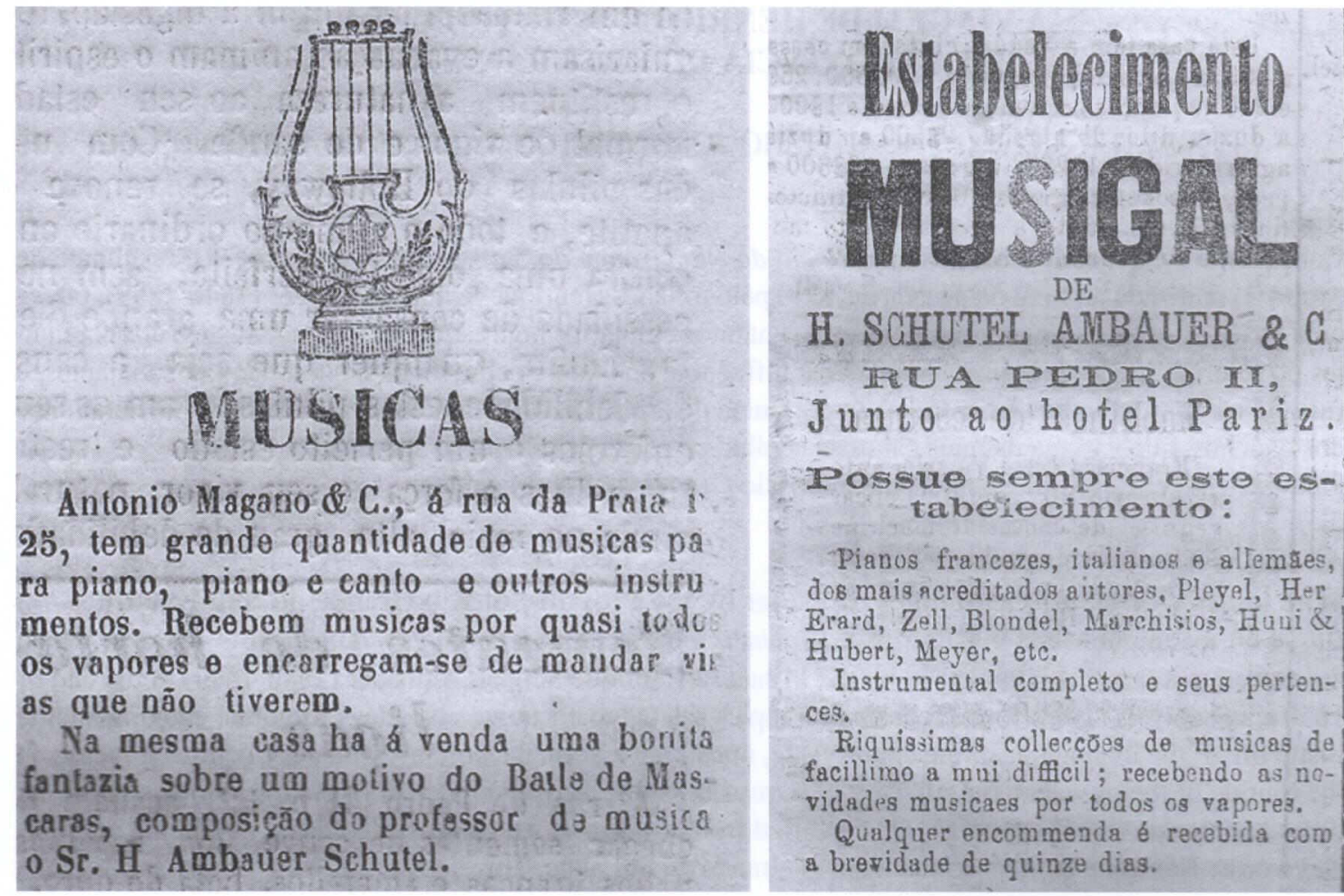

FIGURA 1 - Duas propagandas relacionadas a Henrique Schutel Ambauer, publicadas no "Diário do Rio Grande": a da esquerda, comprova a autoria de uma peça musical baseada na ópera "Un ballo in maschera", de Giuseppe Verdi (edição de 01-9-1865, p. 3); a da direita, informa que o milanês teve uma loja de instrumentos musicais e partituras em anexo ao famoso "Hotel Paris", na cidade do Rio Grande (edição de 08-2-1872, p. 4).

Após o término da viagem, Ambauer radicou-se na cidade do Rio Grande, onde viveu por muitos anos como professor de música, sobretudo para meninas da sociedade local. "Reclames" publicados em periódicos da época (Figura 1), conservados no acervo da famosa "Bibliotheca Rio-Grandense" daquela cidade, atestam sua atividade profissional nessa área, inclusive na composição musical e, mais tarde, no comércio de instrumentos e partituras.

A data do retorno à Europa resta à espera de definição, podendo estimar-se que ocorreu entre os anos de 1877 e 1878, uma vez que a maioria das correspondências por ele enviadas a membros da Società Geografica Italiana ${ }^{4}$ fo-

Lata 106, doc. 22. ram postadas no Rio Grande do Sul até 1877 e, no ano seguinte, já em Milão.

Acerca do nome, não se deve confundir o personagem em foco com o seu tio Henrique Ambauer Schutel, nascido em 1805, na Suíça ou Norte da Itália, que igualmente tinha dotes musicais e viveu no Brasil, onde atuou como médico na cidade do Desterro (atual Florianópolis) e faleceu em 1885, no Rio de Janeiro. ${ }^{5}$ Robert Avé-Lallemant refere-se a ele como "homem de finíssima inteligência e educação", em sua preciosa Viagem pelo sul do Brasil. ${ }^{6}$ Além de participar "ativamente" da "vida cul-

${ }^{4}<$ http://www.archividelnovecento.it/archivinovecento/>. 5 MAAR, J. H. Memória histórica da química em $\mathrm{S}$. Catarina. In: GOLDFARB, J.L. \& FERRAZ, M.M. (Orgs.). Anais, p. 247, 2000 (VII Seminário Nacional de História da Ciência e da Tecnologia).

6 "Nessa ocasião fiquei devendo muitos agradecimentos ao excelente senhor Schüttel, que me forneceu 
tural e social" da capital catarinense, esse tio tornou-se mais conhecido dos historiadores por sua participação na "Empresa Colonizadora Demaria e Schutel", responsável pela implantação da "Colônia Nova Itália", no que hoje é Nova Trento ${ }^{7}$.

Foi por instâncias desse tio, aliás, que Henrique Schutel Ambauer escreveu o Itinerario da Cruz Alta ao Campo Novo da provincia do Rio-Grande do Sul, relatório apresentado ao Dr. Guilherme Schuch de Capanema ${ }^{8}$ e publicado em 1868 na Revista do Instituto Histórico e Geográfico Brasileiro ${ }^{9}$. A publicação desse artigo, por sua vez, motivou a inclusão do autor como sócio-correspondente dessa renomada instituição cultural, aprovada em 11 de setembro de 1868 .

informações sobre as colônias próximas de Biguaçu, Tijucas, Louro, etc. e me mostrou bons mapas especiais e memórias, revelando-se, também, homem de finíssima inteligência e educação" (AVÉ-LALLEMANT, R. Viagem pelo sul do Brasil no ano de 1858. Rio de Janeiro: Instituto Nacional do Livro, 1953. p. 129).

7 PIAZZA, W. A Colonização de Santa Catarina. Florianópolis: BRDE, 1982. p. 94-97.

8 Membro do IHGB, Guilherme Schuch de Capanema foi quem deu parecer favorável à publicação do artigo em foco, constando no mesmo, entre outros elementos, o seguinte depoimento: "Conheci o Sr. Schutel no Desterro em casa do seu tio o ilustrado medico do mesmo nome, pedi-lhe alguns esclarecimentos sobre a provincia do Rio-Grande, que elle havia percorrido; satisfez-me cabalmente: mais tarde pedi-lhe um itinerario para o districto de Campo Novo, que tem interesse geologico por existirem alli jazigos de cobre. Elle ainda n'isso me serviu, e como encontrei no trabalho materia mais apropriada aos fins do Instituto do que a de outras memorias que serviram de titulo de admissão a diversas pessoas, offereci-o e propuz o seu autor para socio. O Sr. Schutel tem mandado correspondencias a nosso favor para as folhas de Milão, de onde é filho" (Revista Trimensal do Instituto Historico Geographico e Ethnographico do Brasil, Rio de Janeiro, tomo XXXI, parte segunda, 1868, p. 380).

9 AMBAUER, H.S. Itinerario da Cruz Alta ao Campo Novo da provincia do Rio Grande do Sul. Revista Trimensal do Instituto Historico Geographico e Ethnographico do Brasil, Rio de Janeiro, 1868, tomo XXXI, parte segunda, 1868, p. 381-394.
Cinco anos mais tarde, despindo-se de certa autocensura que transparece na versão aproveitada pelo austero periódico, o autor reescreveu o Itinerario, ampliando-o com detalhes anteriormente omitidos e que, não raro, são até mais significativos. A respeito do novo texto, datado de 1873 e intitulado A Província do Rio Grande do Sul-Descripção e Viagens, cabe salientar que parte do manuscrito veio a lume na Revista do $I H G B^{10}$, restando inédito um trecho final de 172 páginas, objeto da presente publicação.

Ao se comparar o teor do fragmento aproveitado pelo IHGB em 1888 com o texto inédito, ora em análise, fica patente a radical mudança de valores no lapso de tempo transcorrido. $\mathrm{O}$ texto impresso mostra-se de pouca utilidade nos dias de hoje, uma vez que suas exaustivas informações técnicas encontram-se, obviamente, superadas, carecendo de maior interesse até mesmo para geógrafos e outros profissionais da área. A parte ainda não publicada, ao contrário, por revelar as vivências do autor em suas andanças pelo interior do Rio Grande do Sul, garante-lhe valor permanente, justificando o interesse editorial.

Ao retornar à Itália, Henrique Schutel Ambauer radicou-se em Milão e casou com Carlotta Cazzaniga, vindo a falecer na cidade natal aos 59 anos de idade, em 30 de dezembro de 1899 (Figura 2).

\section{CONSIDERAÇÕES SOBRE A VIAGEM}

Narrado em português fluente e com caligrafia de fácil leitura, o texto inédito da "Viagem" de Ambauer pelo interior do Rio Grande do Sul inclui, de início, referências ao aspecto desolador da costa litorânea da província, vista do oceano, e sobre as dificuldades enfrentadas ao transpor a "barra" do Rio Grande, informando que o percurso do Rio de Janeiro à cidade

\footnotetext{
${ }^{10}$ AMBAUER, H.S. A provincia do Rio-Grande do SulDescripção e viagens. Revista Trimensal do Instituto Historico e Geographico Brazileiro, Rio de Janeiro, tomo LI, parte II, p. 25-72, 1888.
} 


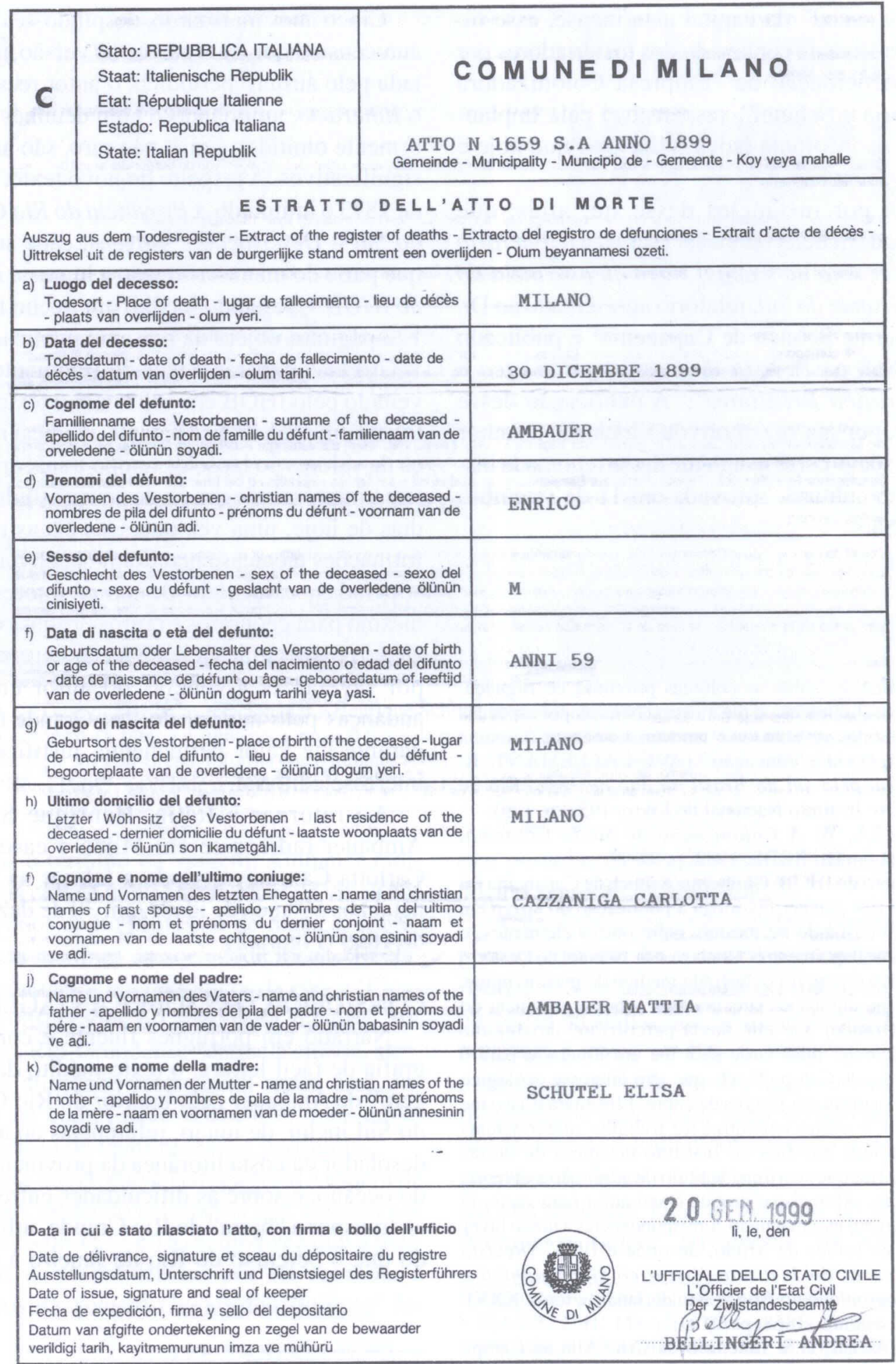

FIGURA 2 - Dados biográficos de Ambauer. Comune di Milano. Estratto dell'atto di morte. Atto n 1659 S. A Anno 1899. Documento firmado por Andrea Bellingeri (L'Ufficiale dello stato civile) e gentilmente fornecido em 1999 pelo Dr. Alberto Cabassi, Consul Geral da Itália em Porto Alegre. 
portuária gaúcha foi feito em cinco dias incompletos, em um barco da Companhia Brasileira de Paquetes a Vapor.

No dia seguinte à chegada na província sulina, o viajante embarcou para Porto Alegre, em percurso que levou 22 horas devido ao forte vento do nordeste. A partir de Itapoã ${ }^{11}$, ele soube apreciar os graciosos contornos do Guaíba e, ao acercar-se à cidade, comparou o seu assentamento com o de Montevidéu, pelo aclive das ruas transversais ao porto. Para o milanês, os arrabaldes eram o que Porto Alegre tinha de "mais agradável" comparado às demais cidades da província, pois "em qualquer ponto que se vá encontram-se golpes de vista verdadeiramente encantadores".

Com a chegada da primavera, Ambauer aceitou o convite de um "distinto cavalheiro" para seguir, com ele, rumo ao oeste da província. $\mathrm{O}$ início da viagem pode ser fixado entre fins de setembro e princípios de outubro de 1858 , segundo indícios constantes no próprio texto, e que serão comentados em seu devido momento, na sequência. Segundo palavras do autor, que omite até mesmo o ano da viagem, ele passou "os meses de inverno em Porto Alegre" e, "quando veio a Primavera", aproveitou o convite anteriormente mencionado para conhecer a "campanha".

Partem, então, em um vapor da "Companhia Jacuhy" ${ }^{12}$ e, tão logo se afastam da capital, cru-

${ }^{11}$ Ponta (e morro) de Itapoã, limite leste do lago Guaíba com a laguna dos Patos. Toda a área de Itapoã é atualmente preservada como "parque estadual".

${ }^{12} \mathrm{O}$ fato de Ambauer ter andado em barco da "Companhia Jacuhy" até Cachoeira do Sul comprova que a viagem aconteceu na primavera de 1858 , pois foi justamente nesse ano que a referida empresa conseguiu a permissão para estender sua rota até essa cidade e a Colônia Santo Ângelo (atual Agudo). O documento oficial previa que os empreiteiros, "independente de subsidio algum, ou de indemnisação de qualquer natureza, igualmente se obrigão a estender as viagens do Rio Pardo até a villa da Cachoeira, e Colônia de Santo Ângelo, ou até suas visinhanças, todas as vezes que no rio Jacuhy houver sufficiente fundo". Fonte: Documentos annexos ao relatorio do presidente da provincia de S. Pedro do Rio Grande do Sul, Ângelo Moniz da S. Ferraz, apresentado a Assembléa Legislativa Provincial na $1^{a}$ sessão da $8^{a}$ legislatura. Porto Alegre, 1858. zam por ilhas comparáveis a "jardins flutuantes", de onde se avistam diversas chácaras e quintas. A ilha do Fanfa, célebre desde a Revolução Farroupilha, não pode ser avistada naquela oportunidade devido a uma chuva que obrigou os passageiros a se retirarem do tombadilho.

O jantar a bordo foi servido antes da primeira parada, nas Charqueadas ${ }^{13}$, ao passarem pela foz do Arroio dos Ratos ${ }^{14}$. Segundo o "uso brasileiro", os criados "colocaram todas as iguarias sobre a mesa, acumulando os doces e a fruta". Depois da sopa, "cada um serve-se à vontade do que lhe agrada, havendo, então, ocasião de observar os gostos mais disparatados".

A viagem continua rio acima e logo encontram a vila de São Jerônimo ${ }^{15}$, para a qual Ambauer antevê certa opulência e riqueza, caso se desenvolva a exploração carbonífera. No lado oposto ao Jacuí, junto à foz do Taquari, ele pode conhecer a vila do Triunfo ${ }^{16}$, decadente desde a "época da revolução" e cuja importância foilhe roubada por São Jerônimo. Aos olhos do viajante, o casario de Triunfo conservava bom aspecto, apesar de abandonado.

Neste ponto do manuscrito e em outro, logo adiante, o autor interrompe a narrativa para reproduzir transcrições de dois trabalhos de Ângelo Cassapi, o primeiro sobre Geologia e Mineralogia e outro, mais extenso, sobre as cachoeiras do rio Jacuí. Natural da Itália, como ele, Cassapi foi um dos primeiros a realizar experiências com o carvão extraído em diferentes

${ }^{13}$ Atual município de mesmo nome, emancipado de São Jerônimo (FORTES, A.B.; WAGNER, J.B.S. História administrativa, judiciária e eclesiástica do Rio Grande do Sul. Porto Alegre: Globo, 1963. p. 391).

${ }^{14}$ Afluente da margem direita do rio Jacuí.

${ }^{15}$ Atual cidade e município de mesmo nome, desmembrado de Triunfo em 3-12-1860. O início do povoamento da sede data de 1800 , a instalação do município deu-se em 30-9-1861 e a elevação da vila à categoria da cidade em 31-3-1938 (FORTES \& WAGNER, 1963. Op. cit., p. 389).

${ }^{16}$ Cidade e município de mesmo nome, desmembrado de Porto Alegre e Rio Pardo por Decreto Regencial de 2510-1831. O início do povoamento da sede data de 1754 e a elevação da vila à categoria de cidade de 31-3-1938 (FORTES \& WAGNER, 1963. Op. cit., p. 442). 
pontos do Rio Grande do Sul, testando seu potencial combustível em um navio de guerra ${ }^{17}$.

Ambauer retoma a narrativa ao partirem, quase ao anoitecer. Às 22 horas, uma nova parada, em Santo Amaro ${ }^{18}$, para o desembarque de passageiros. Neste momento o autor comenta sobre a decadência da vila, as dificuldades de navegação a partir desse ponto, as interferências necessárias para sanar tais obstáculos e os benefícios da construção de uma projetada estrada de ferro no vale do Jacuí.

Depois de Santo Amaro, o barco costeou a ilha do Curral Alto ${ }^{19}$ pelo canal do Furado e, durante a madrugada, deteve-se na "Estância dos Dourados" para o embarque de lenha. Alguns passageiros, munidos de espingardas, aproveitaram a oportunidade para abater aves para o almoço.

Após 23 horas de percurso, desde a capital, o viajante chegou a Rio Pardo ${ }^{20}$, cidade definida como "muito regular em suas ruas, menos algumas que são truncadas". Ele não encontrou "a menor beleza arquitetônica" na igreja matriz, tida como uma das maiores da província, bem como nas capelas de São Francisco e do Senhor dos Passos, descritas como "de pouca aparência".

Em Rio Pardo, Ambauer foi apresentado ao Barão do Triunfo ${ }^{21}$, que lhe propiciou excelen-

${ }^{17}$ BARRETO, A. Bibliografia Sul-Riograndense. Rio de Janeiro: Conselho Federal de Cultura, 1973. v. 1.p. 304305.

${ }^{18}$ Atual Santo Amaro do Sul, distrito do município de General Câmara.

${ }^{19}$ Ilha do rio Jacuí, no município de General Câmara (In: IBGE. Vocabulário Geográfico do estado do Rio Grande do Sul. Rio de Janeiro: Serviço Geográfico do Instituto Brasileiro de Geografia e Estatística, 1950. p. 41).

${ }^{20} \mathrm{Um}$ dos quatro municípios iniciais do Rio Grande do Sul, instalado em 20-5-1811; o início do povoamento da sede data de $1750 \mathrm{e}$ a vila foi elevada à categoria de cidade em 31-3-1846 (FORTES \& WAGNER, 1963. Op. cit., p. 339).

${ }^{21}$ José Joaquim de Andrade Neves (Rio Pardo, 22-1-1807; Assunção, Paraguai, 6-1-1869), herói da Guerra do Paraguai, cognominado "o bravo dos bravos" (CARVALHO, M.T. de. Nobiliário Sul-Riograndense. Porto Alegre: Livraria do Globo, 1937. p. 339-340). te acolhida, e veio a conhecer o padre Filippo Isnardi ${ }^{22}$, "homem sumamente ilustrado", que dispunha de todo o tempo disponível para "estudos de história natural". Italiano, de Savona, esse religioso atuou no Rio Grande do Sul inicialmente em Soledade e, em 1857, assumiu em Rio Pardo. Como em outubro de 1858 ele foi transferido para a paróquia de $\operatorname{Lavras}^{23}$, o registro deste encontro reforça a fixação da data de viagem de Ambauer entre fins de setembro e início de outubro de 1858.

De Rio Pardo, o autor seguiu rio acima, não podendo avistar as diversas cachoeiras existentes por estarem submersas. Embora tenha realizado o trajeto fluvial de 18 léguas até Cachoeira, Ambauer informa que para ali convergiam dois caminhos vindos de Rio Pardo: a "Estrada Real", mais ao norte, pelo cume das coxilhas, passando pelo lugarejo denominado Cruz Alta ${ }^{24}$ e por uma sólida ponte de pedra, em trajeto de doze léguas; e outro mais ao sul, cortando banhados da várzea do Jacuí, com nove léguas.

$\mathrm{O}$ porto de Cachoeira foi alcançado após o término do jantar, em doze horas de viagem a partir de Rio Pardo. Entusiasticamente recebidos por amigos de seu companheiro de viagem, eles subiram a ladeira em um "ômnibus", que os conduziu à vila ${ }^{25}$. Do alto, no Cemitério das Irmandades, ele pode desfrutar de extenso panorama para o oeste, com a cachoeira do Fandango e, mais ao longe, a súbita curva do Jacuí. A respeito da vila, o milanês anotou algumas ruas bem alinhadas, mas não viu edifício algum que lhe chamasse a atenção.

${ }^{22} \mathrm{O}$ padre Isnardi faleceu em Porto Alegre, a 15-6-1860, com 57 anos de idade, de "hemorragia cerebral" (BARRETO, A. 1973. Op. cit., p. 712).

${ }^{23}$ RUBERT, A. História da Igreja no Rio Grande do Sul. Porto Alegre: EDIPUC, 1998. v. 2. p. 125 e 239.

${ }^{24}$ Antigo nome da vila de Bexiga, sede de distrito do município de Rio Pardo.

${ }^{25}$ A vila de Cachoeira foi elevada à cidade em 15-12-1859, pela Lei n ${ }^{\circ} 443$ (FORTES \& WAGNER, 1963. Op. cit., p. 178). 
Como já fizera com a vila de Taquari $^{26}$ e a colônia Santa $\mathrm{Cruz}^{27}$, o cronista dedicou alguns parágrafos a observações sobre outros lugares não visitados. Foi, no entanto, invariavelmente preciso. Assim, ao comentar que de Cachoeira partia uma estrada para o sul, atravessando o passo do Seringa, rumo às vilas de Caçapava ${ }^{28}$ e São Sepé29, aproveitou para descrever sumariamente as duas localidades, destacando que na primeira iniciara, há pouco, a exploração aurífera. $\mathrm{O}$ mesmo procedeu com a cidade de São Gabriel, que das três citadas informa ser a mais importante como centro comercial da Campanha, e com a colônia alemã de Santo Ângelo (atual município de Agudo), recentemente implantada.

Apesar da fertilidade de suas terras, Ambauer atribuiu o escasso progresso da Colônia Santo Ângelo ao isolamento, antevendo uma rápida alteração desse quadro se o traçado da projetada ferrovia viesse a atender a colônia e outras localidades situadas na várzea do Jacuí. Por sua vez, a referência do autor às dificuldades enfrentadas pelos agricultores no escoamento da produção também permite balizar a época da viagem: ela só pode ter acontecido na primavera de 1858 , pois o início do povoamento dessa

${ }^{26}$ Atual cidade e município, emancipado de Triunfo em 47-1849. O início do povoamento da sede deu-se em 1764 e a vila foi elevada à categoria de cidade em 9-7-1891 (FORTES \& WAGNER, 1963. Op. cit., p. 432). Não custa reforçar, todavia, que Ambauer não esteve em Taquari naquela oportunidade.

${ }^{27}$ Antigo nome da atual cidade e município de Santa Cruz do Sul, desmembrado de Rio Pardo em 31-3-1877. A vila foi elevada à categoria de cidade em 19-11-1905 (FORTES \& WAGNER, 1963. Op. cit., p. 351). Não custa repetir que Ambauer não conheceu a Colônia Santa Cruz nessa viagem.

${ }^{28}$ Atual cidade e município, desmembrado dos municípios de Cachoeira, Piratini e Rio Pardo em 25-10-1831. O início de povoamento da sede data de 1783 e a vila foi elevada à categoria de cidade em 9-12-1885 (FORTES \& WAGNER, 1963. Op. cit., p. 174).

${ }^{29}$ Atual cidade e município de mesmo nome, desmembrado dos municípios de Caçapava e Cachoeira em 29-4-1876. O início do povoamento da sede deu-se em 1825 e a vila foi elevada à categoria de cidade em 31-3-1938 (FORTES \& WAGNER, 1963. Op. cit., p. 411). colônia $^{30}$ deu-se em 16-11-1857. Sobre este ponto, pode-se acrescentar que em março do ano seguinte, quando Avé-Lallemant por ali passou, deixou registrado em sua obra de viagem ${ }^{31}$ que a instalação da colônia recém havia iniciado.

A partir de Cachoeira, a viagem seguiu por terra. Acompanhado, agora, por três novos parceiros - um amigo, negociante em Porto Alegre, que encontrara em Cachoeira, e dois peões que carregavam as malas e conduziam os cavalos para as frequentes mudas -, Ambauer tomou o rumo de Santa Maria da Boca do Monte.

Cerca de uma légua ao norte de Cachoeira, a estrada entronca-se com a que vem de Rio Pardo e segue para oeste, em direção ao passo de São Lourenço. Outro ramal vai inicialmente para o norte e, seguindo terras mais elevadas, descreve uma grande volta até alcançar o Passo Real do Jacuí. Conhecedores da região, todavia, os peões escolheram um atalho que, atravessando banhados na várzea, levou os viajantes a precisarem encolher as pernas, por diversas vezes, para não molha-las. Conforme registro textual, o "bom humor" de seu "companheiro de viagem e as canções dos peões" conseguiram distrair o viajante do "desgosto desse contratempo".

Entre Cachoeira e o Passo Real do Jacuí, Ambauer viu casas esparsas e de aspecto paupérrimo, a maioria cobertas de palha, observando ser comum na época das cheias os seus moradores resultarem ilhados, privados dos recursos mais elementares.

Após sete horas de percurso, a caravana chegou ao passo, mas não foi possível vadeá-lo prontamente, pois a travessia morosa de algumas carretas que ali se encontravam ainda demandou algumas horas. No local já se via uma fileira de oito pilares de pedra emergindo da água, de margem a margem.

\footnotetext{
${ }^{30}$ A vila foi criada pelo Decreto $\mathrm{n}^{\circ} 7.199$, de 31-3-1938, e a cidade em 16-2-1959, pela Lei no 3.718 (FORTES \& WAGNER, 1963. Op. cit., p. 153).

${ }^{31}$ AVÉ-LALLEMANT, R., 1953. Op. cit., p. 182.
} 
Ao indagarem as razões pelas quais a pon$\mathrm{te}^{32}$ não fora concluída, foi-lhes dito que o governo provincial avaliara não serem os pilares suficientemente fortes. Ironicamente, transcorridos mais de 150 anos da viagem de Ambauer, os pilares permanecem incólumes, em sua posição original. ${ }^{33}$

A travessia foi realizada em uma flotilha de canoas pelo "velho Alexandre Moreira", que detinha, por contrato, o privilégio exclusivo de passagem. O ponto era bem conhecido na época e Alexandre ali se havia estabelecido desde 1843, pelo menos, segundo indicação colhida no Mappa da Provincia de S. Pedro do Sul, e terrenos adjacentes das provincias limitrofes, publicado por Antonio Ruiz de Araújo no ano indicado.

Ao transporem o rio Jacuí, um dos cavalos conduzido a reboque, preso pelas rédeas, foi levado pela força da correnteza, arrastando a canoa e pondo em perigo ao "teimoso peão". Junto ao passo já existiam algumas casas e o viajante observou que o número delas tendia a aumentar, por ser esta passagem a preferida pelos viajantes que se encaminhavam ao oeste da Província.

A partir do rio Jacuí, avestruzes ${ }^{34}$ e seriemas $^{35}$ passaram a ser encontradas com frequência, mas elas fugiam lépidas com a aproximação dos viajantes.

\footnotetext{
${ }^{32}$ Iniciada em 1848, a ponte do Passo Real do Jacuí foi colocada em uso somente em 1872. Em 1893, durante a Revolução Federalista, combatentes atearam fogo em seu último vão para impedir a passagem dos adversários, e a ponte jamais foi recuperada (BRONDANI, D. A malfadada ponte do Jacuí. In: Diário de Santa Maria, 23/1/2010).

${ }^{33}$ Até meados da década de 1990 , todos os pilares permaneciam em sua posição original. Segundo informação do balseiro do lugar, o primeiro pilar da margem direita tombou nessa época, em decorrência de uma grande enchente, de modo que atualmente é visto apenas em períodos de seca e, mesmo assim, quase recoberto pela vegetação.

${ }^{34}$ A ema (Rhea americana), em verdade.

${ }^{35}$ Nome vulgar atribuído a Cariama cristata, entre outras espécies da família dos Cariamídeos. Trata-se de aves terrestres, que preferem caminhar a voar.
}

Logo adiante, quase foram envolvidos em uma peleia ao pararem em uma venda, pelo simples fato de um companheiro ter recusado o convite para beber "aguardente" com os "carreteiros" que se encontravam "junto ao balcão". O gesto foi interpretado como "insolência" e um dos carreteiros proferiu "várias palavras grosseiras" ao companheiro de viagem que, "pouco habituado a isto, deu-lhe um soco que o estendeu ao chão". Segundo registro de Ambauer, foi necessária a sua intervenção "para que não houvesse sangue", resolvendo-se o problema com o oferecimento de uma "garrafa de vinho do porto aos carreteiros" que, enfim, se acalmaram.

Seguindo viagem, passaram pelo lugarejo conhecido por Enforcados, onde havia "uma casa de negócio e outras de moradia”. Cabe notar que a localidade, conforme o Mappa da provincia de San Pedro, que acompanha os Annaes da Provincia de S. Pedro ${ }^{36}$, do Visconde de São Leopoldo $^{37}$, fica no lado oposto do Jacuí e mais perto de Cachoeira, portanto. A explicação para esse equívoco pode ser atribuido, contudo, ao longo intervalo de tempo entre a realização da viagem e a redação do manuscrito.

Retomando a viagem, o grupo passou pela "Restinga Seca"38, por um cemitério cercado no meio do campo e pelo "Arroio do Sol", local em que havia uma venda de aspecto miserável.

${ }^{36}$ Verdadeiro clássico da historiografia do Rio Grande do Sul, essa obra teve sua primeira edição publicada em Paris (Tip. de Casimir, 1839) e completa duas anteriores, intituladas Annaes da Capitania de São Pedro do Rio Grande do Sul (Rio de Janeiro, Imprensa Régia, 1819) e outra que veio a lume com o mesmo título da edição francesa (Annaes da Província de São Pedro), embora publicada no Rio de Janeiro (1822), pela Imprensa Nacional (MARTINS, A. Escritores do Rio Grande do Sul. Porto Alegre: Ed. da Universidade Federal do Rio Grande do Sul : Instituto Nacional do Livro, 1978. p. 439).

${ }^{37}$ José Feliciano Fernandes Pinheiro (Santos, 9-5-1774; Porto Alegre, 6-7-1847), verdadeiro patriarca da historiografia do Rio Grande do Sul. De sua produção literária destaca-se, ainda, a célebre "Memórias" (CARVALHO, 1937. Op. cit., p. 241-242).

${ }^{38}$ Atual cidade e município de mesmo nome, desmembrado de Cachoeira do Sul em 1959 (FORTES \& WAGNER, 


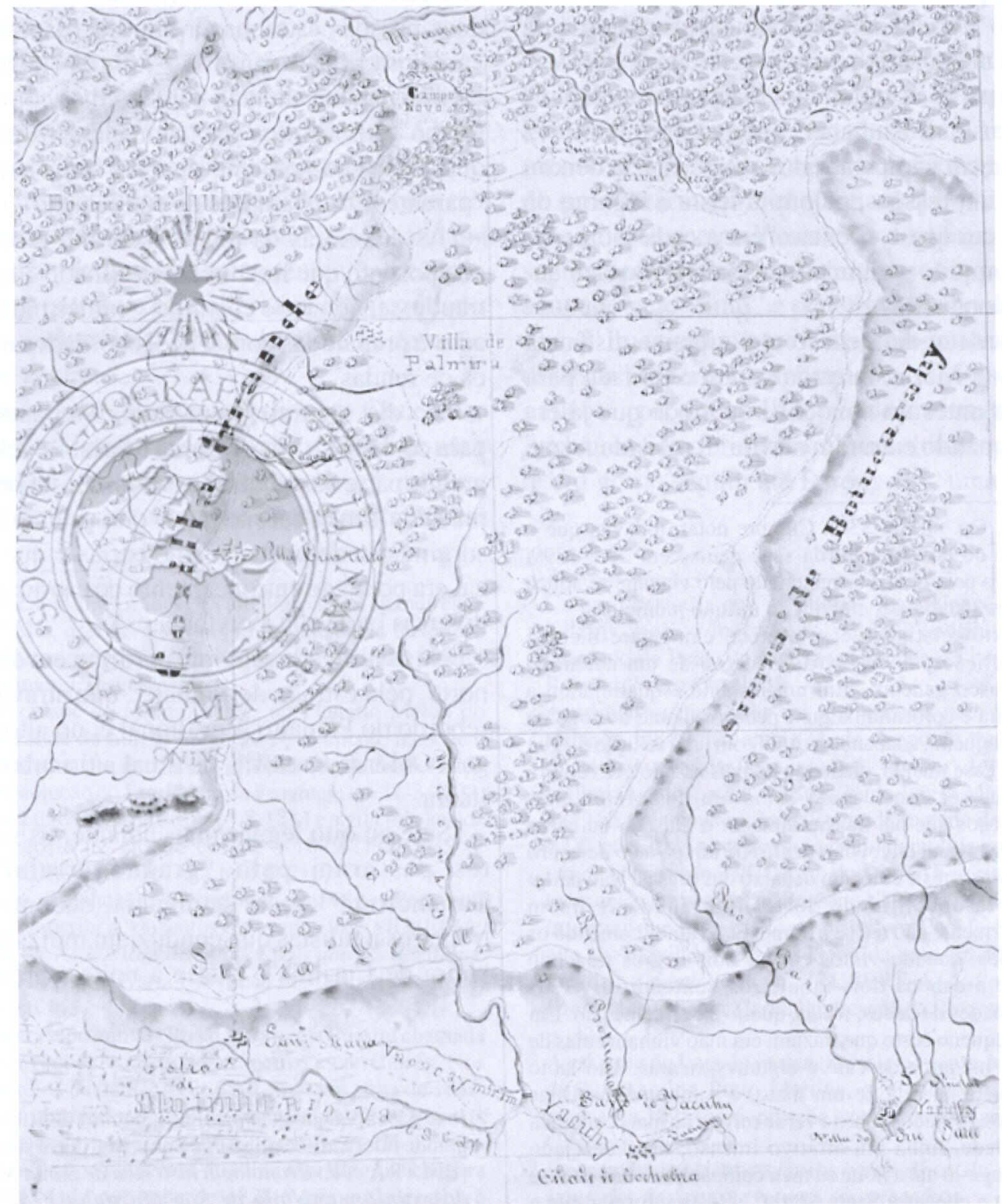

FIGURA 3 - Itinerário parcial da viagem de Henrique Schutel Ambauer. Plano do Municipio de Cruz Alta na provincia de S. Pedro do Rio Grande do Sul / Foi levantado por indicações do Sr. D. Enrique Ambauer Schutel y desinhado por Adolfo Del Pieco [!]. Carta manuscrita digitalizada. Pertence ao acervo da Biblioteca da Societá Geografica Italiana, em Roma; a cópia está disponível na rede mundial por iniciativa de Internet Culturale. Cataloghi e collezioni digitali delle biblioteche italiane. 
Cumpre notar que o último ponto corresponde ao atual "Arroio do Só", sede de um distrito do município de Santa Maria.

No "Arroio do Sol", como o proprietário da venda negou-lhes pouso, pernoitaram ao relento. Os peões acenderam o fogo e estenderam os arreios. Para Ambauer, que pela primeira vez dormia em campo aberto, a experiência deixou fortes impressões, pelo tom triste e lúgubre da noite, em que o silêncio "era a cada momento interrompido por um grito estranho" ou "lamento prolongado".

Mais um dia pela frente: a pouca distância de Santa Maria, interromperam a jornada para sestear antes do almoço ${ }^{39}$, de modo que já era noite quando entraram na vila ${ }^{40}$, parando frente

1963. Op. cit., p. 336). Cumpre notar, todavia, que o início do povoamento da sede deu-se em 29-7-1899, motivo pelo qual o termo citado pelo viajante se aplica a outra localidade, embora do mesmo município.

${ }^{39} \mathrm{O}$ texto relativo a esse almoço campestre merece transcrição pelo registro fidedigno de um autêntico churrasco gaúcho: "Em um instante esquartejaram a terneira e colocaram alguns pedaços diante do fogo de uma fogueira, adubando a carne com uma solução d'água e sal. Esse manjar, chamado no país assado com couro, merece ser considerado como um dos pratos mais saborosos que há. Fazem também o guisado ou carne picada, a qual envolvem dentro de um pedaço de couro da própria rês e colocam debaixo das brasas. Não parou nisso a amabilidade do tal indivíduo, de quem infelizmente não retive o nome. Estávamos comendo os assados, quando vimos chegar dois negros trazendo sobre a cabeça dois tabuleiros contendo diversas qualidades de doces, frutas, queijo e excelente pão. Em um pequeno cesto que traziam em mão vinham cuias de mate, máquina de café e algumas xícaras. Tão lauto banquete na orla de um mato, à sombra de vetustas árvores, sentados sobre a verde relva e na mais completa liberdade, tinha um atrativo imenso; teria desejado prolonga-lo até a noite se meu companheiro não tivesse pressa a chegar a Santa Maria". Resta informar que a "carne picada" envolta em couro e assada sob as brasas constitui uma rara descrição do chamado "churrusco", de acordo com informação pessoal do historiador Tau Golin.

${ }^{40}$ A vila e sede do município foi criada pela Lei $\mathrm{n}^{\circ} 400$, de 16-12-1857, e a instalação do mesmo deu-se em 17-51858 , poucos meses, portanto, antes da visita do milanês. O início do povoamento da sede ocorreu em 1797. A vila de Santa Maria foi elevada à categoria de cidade em 6-4-1876, pela lei no 1013 (FORTES \& WAGNER, 1963. Op. cit., p. 355). à casa do Coronel Valençą ${ }^{41}$. Muito hospitaleiro, o "ilustre coronel" convidou-os para juntarse à ceia que, segundo o cronista, teve "vinte $\mathrm{e}$ duas pessoas estranhas à família". Isolina ${ }^{42}$, a "graciosa filha do anfitrião", fez as "honras da casa", costume anotado pelo cronista como "estranho" aos hábitos da "campanha", uma vez que a família somente aparece em visitas de "parentes" ou "famílias de sua relação".

Às dez horas da noite "cada um retirou-se ao aposento que lhe tinham destinado", encontrando-se, como de costume, "camas mui asseadas e preparadas com lençóis bordados e cheios de rendas".

No dia seguinte, bem cedo, Ambauer saiu para conhecer a vila de Santa Maria. Revela que grande parte da população era composta por alemães ou seus descendentes, que principiava o surgimento de pequenas indústrias e que o local era ponto de entroncamento de estradas para diversas partes da Província.

Na madrugada seguinte partiram em direção norte, pela estrada do Pinhal ${ }^{43}$, que atravessa o rebordo do Planalto Meridional e, no alto, chega à Colônia Kroeff ${ }^{44}$, no atual sítio urbano de Itaara.

Sete ou oito léguas mais adiante, os viajantes passaram pelo "grande arraial" de Tupanciretã ${ }^{45}$ e, na sequência, encontraram tropeiros paulistas que conduziam mulas para a "feira de Curitiba". Quase à noite, aproxima-

${ }^{41}$ José Alves Valença (1811-1866), natural de Rio Pardo, grande líder e chefe militar de Santa Maria em sua época (BELTRÃO, R. Cronologia histórica de Santa Maria e do extinto município de São Martinho 1787-1930. Canoas: La Salle, 1979. 582 p.).

${ }^{42}$ Isolina Alves Valença (1842-1865). Fonte: BELTRÃO, R. Op. cit., p. 105.

${ }^{43}$ Trata-se da "estrada velha do perau", pela qual ainda hoje se pode chegar a Itaara, a partir do final da rua Euclides da Cunha, na cidade de Santa Maria.

${ }^{44}$ Então recentemente criada (outono de 1857), para assentamento de imigrantes alemães.

${ }^{45}$ Atual cidade e sede do município de mesmo nome, assentada no divisor de águas entre as bacias do Jacuí e Uruguai. 
ram-se do lugar conhecido por Espinilho ${ }^{46}$, sendo bem recebidos na venda de um italiano, onde puderam secar as roupas molhadas por uma tempestade.

Tendo partido cedo, na manhã seguinte, às dez horas da manhã os viajantes alcançaram a vila de Cruz Alta ${ }^{47}$, apeando à porta da casa de negócio de Santhiago Gandulfo, um italiano que havia enriquecido no comércio ${ }^{48}$ e cuja casa era um tipo de "hospedaria gratuita" dos "viandantes", uma vez que sua mesa reunia "o peão de tropa e o patrão, o oficial graduado e o soldado raso, o eleitor ou o deputado ao lado do mais ínfimo votante".

Tendo permanecido três dias em Cruz Alta, Ambauer informa que a vila constitui-se de uma grande rua ${ }^{49}$ que desemboca na praça ${ }^{50}$ da igre$\mathrm{ja}^{51}$ e outras paralelas, com poucas edificações.

${ }^{46}$ Atual Espinilho Grande, localidade entre Tupanciretã e Cruz Alta, que deve seu nome à abundância da árvore homônima na região (Vachellia caven (Molina) Seigler \& Ebinger, Fabaceae).

${ }^{47}$ Atual cidade de mesmo nome, no Planalto Médio do Rio Grande do Sul. O início do povoamento da sede é atribuído ao ano de 1810 , a criação da vila foi definida por Resolução do Presidente da Província em 11-3-1833, o município foi instalado em 4-8-1834 e a vila foi elevada à categoria de cidade em 12-4-1879 (FORTES \& WAGNER, 1963. Op. cit., p. 209-210).

48 "Quase analphabeto", amealhou com o comércio um capital superior a "duzentos contos de réis" (SILVEIRA, H.J.V. da. As Missões orientais e seus antigos domínios. Porto Alegre: Livraria Universal de Carlos Echenique, 1909. p. 343).

${ }^{49}$ Trata-se da primitiva "Rua das Carretas", assim chamada por ser rota de trânsito dos tropeiros e carreteiros. Nos primórdios da fundação de Cruz Alta, por volta de 1830, era denominada de "Rua da Olaria", pois em sua extremidade norte existiu a primeira olaria da vila, construída por Vidal José do Pilar, morador que chegara na localidade por volta de 1828. Mais tarde passou a chamar-se "Rua do Commercio", por abrigar a maioria das casas comerciais da cidade. Por decreto de 08 de maio de 1940, firmado pelo prefeito Pacífico Dias da Fonseca, a rua passou a chamar-se "Pinheiro Machado", em homenagem ao senador José Gomes Pinheiro Machado, que nasceu em uma casa ao lado do Clube do Comércio, nessa mesma via pública (comunicação pessoal do historiador Rossano Viero Cavalari).

${ }^{50}$ Desde o início da história de Cruz Alta essa praça recebeu, sucessivamente, os nomes de "Praça da Egreja", da Matriz, Rio Branco e, finalmente, Érico Veríssimo.
O cronista atribui-lhe certa importância comercial, como centro de convergência da produção dos ervais e local de passagem das "tropas de mulas” para a província de São Paulo.

Com mau tempo, cinco léguas adiante de Cruz Alta os viajantes pararam para pouso na Estância do Lagoão ${ }^{52}$, ao norte do arroio de mesmo nome. Ao amanhecer, apesar do convite do proprietário para que aguardassem em sua casa até o tempo melhorar, eles decidiram prosseguir, enfrentando um "chuvisqueiro que caia açoitado pelo vento" e penetrava no "poncho e roupa" que tinham por baixo, enregelando "até os ossos". O terreno argiloso tornou-se escorregadio $^{53}$, provocando a queda do cavalo de Ambauer. Sem ferimento, ele montou novamente e o grupo seguiu até Porongos ${ }^{54}$, uma légua

Cumpre destacar que as últimas denominações "não colam", pois o logradouro público continua a ser chamado de Praça da Matriz (comunicação pessoal de Rossano Viero Cavalari).

${ }^{51}$ A primeira capela, que foi a conhecida pelo viajante milanês, foi erigida em 1824, ao tempo do traçado da povoação, e persistiu em pé, apesar de parcos melhoramentos, até a construção da Igreja Matriz, em 1873. A bela construção da segunda metade do século XIX, com duas altas torres, acabou demolida em 1947, para a construção da Catedral do Divino Espírito Santo (comunicação pessoal de Rossano Viero Cavalari). Resta informar que foi ao lado da primitiva Capela, bem no alto da "coxilha", que foi "erguida uma grande cruz, que deu o nome ao lugar" (RUBERT, A. A diocese de Santa Maria. Santa Maria: Publicação da Diocese, 1957. p. 32).

${ }^{52}$ A estância do Lagoão pertenceu, inicialmente, à família de Athanagildo Pinto Martins, que chegou naquelas plagas em 1825 (comunicação pessoal de Rossano Viero Cavalari).

${ }^{53}$ Descrição precisa: os solos vermelhos da região, saturados de água, se tornam escorregadios.

${ }^{54}$ Situada quase em frente à estância de Athanagildo Pinto Martins, foi em Porongos que se deu um importante combate da Guerra dos Farrapos, no dia 07 de junho de 1837, entre as forças imperiais da Leal Divisão CruzAltense, comandada por Vidal José do Pilar e Antonio de Mello Albuquerque, o "Mello Manso", e as forças de Bento Manoel Ribeiro, que estava conferenciando com Rodrigo Felix Martins (irmão de Athanagildo). Mesmo ferido, Bento Manoel protagonizou uma fuga espetacular no lombo de um cavalo, escapando da refrega (comunicação pessoal de Rossano Viero Cavalari). 
adiante. No local havia cinco ou seis casas de aspecto paupérrimo, entre as quais duas vendas. "Entramos em uma delas e pedimos cognac para restituirmos a circulação do sangue. Nada tinham porém nessas vendas, apenas podiamme vender um cálice de cachaça, o qual o meu companheiro batizou com o nome de FineChampagne".

Em Porongos, foram informados que um comboio de carretas os precedia na direção de Campo Novo. Logo os alcançaram, jantaram com os carreteiros e, como a chuva continuava e o frio era intenso, resolveram dormir em uma carreta coberta de couros e com paredes laterais de capim santa-fé ${ }^{55}$.

Um dos carreteiros informou que a pouca distância vivia o Major Victor ${ }^{56}$, francês muito hospitaleiro e em cuja casa ${ }^{57}$ os viajantes ficariam bem acomodados. A noite foi "das mais aprazíveis", por ser o hospedeiro "homem inteligente e ilustrado", de modo que foi agradável ouvi-lo falar sobre "suas campanhas" e "longas viagens".

${ }^{55}$ Panicum prionitis Nees (Poaceae), gramínea de terrenos pantanosos, usada, tradicionalmente, para "quinchas", isto é, para cobertura de construções, em substituição a telhas. O capim Santa-Fé é espécie nativa no sul do Brasil, Paraguai, Uruguai e Argentina.

${ }^{56}$ Trata-se de Victor Dumoncel, nascido em Cherbourg (Normandia, França), em 21 de julho de 1814. Na juventude, foi preso em Paris por ter-se envolvido em movimentos estudantis, mas conseguiu fugir, embarcando para a Argentina. Lá se alistou no exército, tornando-se major por atos de bravura. Abandonou a carreira militar em 1850 , passando a dedicar-se ao tropeirismo, razão pela qual acabou se estabelecendo onde Ambauer o encontrou. Dumoncel faleceu em Passo Fundo, em janeiro de 1888. Fontes: ECKER, A. A trilha dos pioneiros. Passo Fundo: Berthier, 2007; <http:// www.gencircles.com/users/valdenei/11/data/12710> e h t tp://www.orkut .com/ Com m M g s ? $\mathrm{cmm}=2519259 \& \mathrm{tid}=5511112806878228377>$.

${ }^{57} \mathrm{O}$ viajante refere-se à Fazenda Capão Grande, onde o Major Victor Dumoncel passou a residir após seu casamento com Margarida Lírio, filha do português Manuel Vicente Lírio, proprietário rural de Cruz Alta. O Major Victor Dumoncel era avô do Coronel Victor Dumoncel Filho (este, filho de outro homônimo), chefe político com destaque na Revolução de 1923 (comunicação pessoal de Rossano Viero Cavalari).
Os cavalos que conduziram Ambauer e seus companheiros ficaram descansando na invernada do anfitrião, que lhe ofereceu outros melhores, com os quais prosseguiram a jornada. A cerca de uma légua da casa do francês encontraram o arroio da Palmeira, facilmente vadeável, mesmo estando cheio e correntoso. Seguindo o caminho, do alto de uma colina avistaram um grupo de vinte a trinta casas: era a "vilinha da Palmeira" 58 , para onde eram encaminhadas as "ervas do erval da Guarita e adjacências". Na vila, onde também se achava a "Comissão Científica da estrada do Alto-Uruguai", pernoitaram em "modestíssima venda", no passo do Novaes ${ }^{59}$.

No dia seguinte, chegaram ao anoitecer à estância de um velho paulista, juiz de paz da Freguesia, onde puderam presenciar o julgamento de um "ladrão de vacas" ${ }^{60}$ a quem os "vizinhos tinham agarrado, amarrado de pés e mãos, e conduzido à presença do velho". Por intercessão de Ambauer, o indivíduo que seria "estaqueado" teve a pena comutada para um mês de prisão.

Partindo cedo, ao amanhecer, avistaram sem demora a picada que leva ao Campestre ${ }^{61}$ do Campo Novo $^{62}$ e encontraram a casa de negóci-

\footnotetext{
${ }^{58}$ Atual cidade de Palmeira das Missões. O município, desmembrado de Cruz Alta e Passo Fundo, foi instalado em 7-4-1875 (FORTES \& WAGNER, 1963. Op. cit., p. 307).

${ }^{59}$ Provável referência ao major Antonio de Novaes Coutinho, "que obteve do commando da fronteira das Missões, mais de 6 léguas no rincão da Guarita, e fundou grandes estâncias" (SILVEIRA, 1909. Op. cit,, p. 417).

${ }^{60} \mathrm{Na}$ tradicional economia pastoril, o furto de gado alheio era crime geralmente considerado mais grave do que o assassinato.

${ }^{61}$ "No Campo Novo (...) abundam o capim barba de bóde e o denominado capim limão, duas pragas que só com bastante trabalho podem ser extirpadas" (SILVEIRA, 1909. Op. cit., p. 415-416). Ao citar a barba-de-bode (Aristida sp.) e o capim-limão (Elionurus sp.), Hemetério Veloso da Silveira informa, por tabela, que o solo da região deve ser mais arenoso do que o comum no Planalto Médio.

${ }^{62}$ Atual município do noroeste do Rio Grande do Sul, fundado em 03-7-1959. A história conta que João Vicente Souza foi o primeiro habitante a se estabelecer nessa
} 
os do italiano Pedro Paggi ${ }^{63}$, de quem receberam franco acolhimento. Do cume de uma colina, deslumbraram-se com a visão panorâmica da exuberante floresta do Alto Uruguai, com seus troncos de grandes diâmetros, os cipós e o tapete de folhas secas no chão, onde os raios do sol não podiam penetrar: "Por todos os lados o horizonte estava obscurecido por uma barreira verde-negra da soberba vegetação dos matos seculares, contrastando com o azul do céu deslumbrante de luz".

No dia seguinte, costeando a margem esquerda do Turvo ${ }^{64}$, passaram pelo Povinho, "aglomeração de dez a doze casas de palha e alguns engenhos", de onde seguiram para São Xavier, "povoação (...) de trinta a quarenta casas de pobríssimo aspecto, uma ou outra coberta de telha", em cuja "extremidade sul se vê uma capelinha sob um largo, sucedendo-se na margem esquerda do arroio os engenhos desse ponto".

Em São Xavier, foram acolhidos em casa do Capitão João Pedro de Campos ${ }^{65}$, principal autoridade policial do distrito de Campo Novo. A respeito da "população dos ervais", estimada por Ambauer em 2.000 indivíduos, ele registrou que em "grande parte" é formada de "desertores dos batalhões de linha, de indivíduos de equívocos precedentes" e de "mulheres de pouquíssima consideração, com quem vivem livremente".

região (1834) habitada por índios caingangues, com o objetivo de extrair erva-mate dos famosos ervais nativos.

${ }^{63}$ Estabelecido no Campo Novo, o italiano Pedro Paggi retirou-se para além do rio Uruguai, pouco depois da passagem de Ambauer pela região. O ponto da margem oposta do Uruguai em que ele se estabeleceu, no território de Corrientes, foi chamado de "Porto Paggi", mas a povoação "está quase extincta", pois muita gente voltou para os "rehabilitados hervaes brasileiros" (SILVEIRA, 1909. Op. cit., p. 442).

${ }^{64}$ Importante afluente da margem esquerda do rio Uruguai.

65 "No local do Campo Novo, em frente ao engenho de João Pedro de Campos, quando existiam cerca de 20 casas, os cidadãos (...) resolveram erigir uma capella dedicada a São José"' (SILVEIRA, 1909. Op. cit., p. 422). A nota esclarece a denominação do povoado, bem como o orago da capela referida pelo milanês.
Acompanhados pelo Sr. Campos, os viajantes estiveram em diversos engenhos, dos quais oferece uma minuciosa descrição dos processos envolvidos no preparo da erva-mate.

A viagem de retorno foi apressada, pois seu amigo e companheiro fora chamado com urgência. Em três dias estavam em Cruz Alta e em oito em Cachoeira, onde embarcaram em um lanchão que os levou a Porto Alegre em mais dois dias e meio.

Antes de encerrar a sua narrativa, o jovem Ambauer acrescenta um comentário que ainda soa atual, infelizmente: "Quanta riqueza se destrói hoje com o sistema de abater e queimar o bosque para plantar meia dúzia de pés de milho, feijão ou outro legume para a alimentação dos erveiros".

\section{REFERÊNCIAS BIBLIOGRÁFICAS}

AMBAUER, H.S. Itinerário da Cruz Alta ao Campo Novo da província do Rio Grande do Sul. Revista Trimensal do Instituto Historico e Geographico do Brasil, Rio de Janeiro, 1868, tomo XXXI, parte segunda, p. 381-394.

AMBAUER, H.S. A provincia do Rio-Grande do Sul - Descripção e viagens. Revista Trimensal do Instituto Historico e Geographico Brazileiro, Rio de Janeiro, tomo LI, parte II, p. 25-72, 1888. AVÉ-LALLEMANT, R. Viagem pelo sul do Brasil no ano de 1858. Rio de Janeiro: Instituto Nacional do Livro, 1953. v. 1. 398 p.

BARRETO, A. Bibliografia Sul-Riograndense. Rio de Janeiro: Conselho Federal de Cultura, 1973. v. $1.736 \mathrm{p}$.

BELTRÃO, R. Cronologia histórica de Santa Maria e do extinto município de São Martinho 1787-1930. Canoas: La Salle, 1979. 582 p.

BRONDANI, D. A malfadada ponte do Jacuí. In: Diário de Santa Maria, 23/1/2010.

CARVALHO, M.T. de. Nobiliário Sul-Riograndense. Porto Alegre: Globo, 1937. 371 p.

ECKER, A. A trilha dos pioneiros. Passo Fundo: Berthier, 2007.

FORTES, A.B.; WAGNER, J.B.S. História administrativa, judiciária e eclesiástica do Rio Grande do Sul. Porto Alegre: Globo, 1963. 497 p. 
IBGE - Instituto Brasileiro de Geografia e Estatística. Vocabulário Geográfico do Estado do Rio Grande do Sul. Rio de Janeiro: Serviço Geográfico do Instituto Brasileiro de Geografia e Estatística, 1950. 153 p.

MAAR, J.H. Memória histórica da química em S. Catarina. In: GOLDFARB, J.L.; FERRAZ, M.M. (Orgs.). Anais, 2000. (VII Seminário Nacional de História da Ciência e Tecnologia). p. 241-250.

MARTINS, A. Escritores do Rio Grande do Sul. Porto Alegre: Ed. da Universidade Federal do Rio Grande do Sul: Instituto Nacional do Livro, 1978. $636 \mathrm{p}$.

PIAZZA, W. A colonização em Santa Catarina. Florianópolis: BRDE, 1982. p. 94-97.

RUBERT, A. A diocese de Santa Maria. Santa Maria: Publicação da Diocese, 1957. 250 p.

RUBERT, A. História da Igreja no Rio Grande do Sul. Porto Alegre: EDIPUC, 1994. v. 2. 181p.

SILVEIRA, H.J.V. da. As Missões Orientais e seus antigos domínios. Porto Alegre: Livraria Universal de Carlos Echenique, 1909. 702 p.
Sites:

<http://www.gencircles.com/users/valdenei/11/data/ 12710>. Acesso em: 12 jul. 2011

$<$ http://www.orkut.com/CommMsgs?cmm=2519259\&tid $=5511112806878228377>$. Acesso em: 12 jul. 2011.

$<$ http://www.archividelnovecento.it/archivinovecento/>. Acesso em: 12 jul. 2011.

\section{Fontes:}

Documentos annexos ao relatorio do presidente da provincia de S. Pedro do Rio Grande do Sul, Angelo Moniz da S. Ferraz, apresentado a Assembléa Legislativa Provincial na $1^{a}$ sessão da $8^{a}$ legislatura. Porto Alegre, 1858.

Revista Trimensal do Instituto Historico e Geographico Brazileiro (tomo LI, parte II, 1888).

Revista Trimensal do Instituto Historico Geographico e Ethnographico do Brasil (tomo XXXI, parte segunda, 1868).

Relatorio do presidente da provincia de S. Pedro do Rio Grande do Sul, Angelo Moniz da S. Ferraz, apresentado á Assembléa Legislativa Provincial na $1^{a}$ sessão da $8^{a}$ legislatura. Porto Alegre, Typ. do Correio do sul, 1858. 